\title{
Body Talk: Moving Beyond Speech When Analysing Literature Discussions
}

\author{
STIG-BÖRJE ASPLUND \\ Karlstad University, Sweden
}

\begin{abstract}
The intent of this article is to promote a methodological approach to the analysis of literature discussions by adopting a conversational analytic approach that views embodied actions (including talk) as multimodal. It is argued that this analytic approach moves beyond previous studies that focus on talk only, when analysing literature discussions, and further, that such an approach contributes to an increase in our understanding of the complex meaning-making processes that are set into play when students interact on literary texts in school.
\end{abstract}

Keywords

literature discussion, embodiment, conversation analysis, multimodality, interaction

\section{Introduction}

During their time at school children and young people alike interact with a great variety of texts which they may process in different ways in the classrooms. Regarding their encounters with literary texts there is in our schools a strong belief in literature discussions as a form of a teaching and learning process. With a point of departure from a sociocultural perspective on learning and development (Säljö, 2011), the literature discussion is seen as a significant pedagogic element through which different readers will have an opportunity to join in dialogues with each other about their readings. The fundamental idea is to let students sit together, with or without their teachers' direct participation, in small groups and discuss the same literary text they have read. Such literature discussions are supposed to create opportunities for various readings and perspectives to be met and confronted with each other, with the aim of supporting children and young people as developing readers (see Tengberg, 2011, for a more extensive discussion).

One important notion in this development is the the reader response theory perspective that emphasises the dialogic element between the reader and the text in the reading process (McCormick, 1994). Under the influence of Louise Rosenblatt's work (1938/1995, 1978/1994) on the act of reading and her theories - reader response theory and transactional theory - we now know the importance of creating opportunities in our classrooms where our students can respond to texts according to their own unique lived-through experience. In fact, in her work, Rosenblatt even argues that we perhaps should consider "the text as an even more general medium of communication among readers" (Rosenblatt, 1978/1994, p. 146) where different readers can interact and discuss their interpretations in order to develop as readers and as citizens in a democratic society.

Research on literature discussions in school settings has generated increased interest recently, probably mainly due to the emphasis in various research contexts on the importance of collective forms of learning, such as classroom discourse and discussions, for students' learning processes (Chinn et al., 2001; Langer, 2011; Nystrand, 1997, 2006; Soter et al., 2008).

Many of these studies on literature discussions examine, with different discussion approaches and with different aims, how the use of group discussions can help students promote 
high-level comprehension and responses to texts (Almasi et al., 2001; Annmarkrud \& Bråten, 2012; Chinn et al., 2001; Evans, 2002; Maloch, 2002; Marshall, 1989; Murphy et al. 2009; Raphael et al., 1998; Reninger, 2007). There is also a growing body of research that focuses on different identity construction aspects that take place in literature discussions and examines how these correspond with the readers' reception of the literary text and how students construct themselves as readers in a school context. Many of these studies also deal with power issues circulating in these literature discussions. Gender has been a thoroughly studied topic (Dutro, 2001; Evans, 1996a, 1996b; Evans et al., 1997) and there are also studies that examine how racial-identity formations are constructed in literature discussions (Rogers \& Mosley, 2006). Asplund $(2010,2012)$ examines how adolescent boys construct class and gender in literature discussions, and in another study, Asplund \& Pérez Prieto (2013) show how adolescent boys use literature discussions in the construction of identity and place.

Research on literature discussions is often done through video recordings, which is the case in the majority of the studies mentioned above. Video-based methods offer many opportunities for the researcher to evidence things in the interaction in a completely different way than audio recordings can, which has led to an increase over the past decade in the use of video recordings in the research on literature discussions. Common to these studies is that they focus on spoken language in their analyses of the literature discussions. Although video recordings also register the visual aspects of who or what the participants are directing their attention to, and how participants use their bodies and physical objects in the environment as semiotic resources, little interest (with the exception of Asplund, 2010, 2012 and Asplund \& Pérez Prieto, 2013) has been given to adopting a multimodal approach to the study of literature discussions. In this article, such an approach will be used, with the aim of examining how multiple semiotic resources are attended to, collaboratively recognised and integrated into the ongoing organisation of a literature discussion.

\section{Studies of Multimodal Interaction}

The study of multimodal interaction has been carried out from a number of different perspectives. What these studies have in common is that they deal with embodied interaction in the material world, including material objects in the surrounding environment, in the process of meaning-making and action formation. The term "multimodal(ity)" has been used by various groups of researchers in the study of human interaction. From the perspective of the social semiotic research paradigm (Jewitt \& Kress, 2003; Kress 2010; Kress \& van Leeuwen, 2001) there are several studies that focus on communication and meaning-making practices in school contexts. Some examine how different school subjects such as Science, Geography and English are shaped by the organisation of different semiotic resources (Kress et al., 2001; Kress et al., 2005; Taylor, 2012). Others focus on if and how different digital media can promote the construction and reconstruction of knowledge, learning and literacy (Jewitt, 2003, 2005, 2008), how drama, visuals and music are used by students to interpret texts and to construct meanings (Lee, 2013), or the use and representation of multimodal texts in kindergarten (Granly \& Maagerø, 2012) and in learners filmmaking practices (Gilje, 2009).

In another line of research, with an approach that will be adopted in this article, examinations have been made of how participants simultaneously use multimodal resources to organise their interactions. This kind of analysis (conversation analysis; henceforth CA) focuses on how multimodal resources contribute to the ongoing interaction, and studies how these multimodal resources are coordinated in interaction between participants (Goodwin, 2000, 2003, 
2007; Goodwin \& Goodwin, 2012). This research has been carried out in a range of different contexts, including educational settings (see e.g., Asplund \& Kilbrink, 2016; Käntää, 2014; Melander \& Sahlström 2009; Tabensky, 2008). While the social semiotic approach tends to focus on the semiotic products independently of whether and how the participants orient to them, CA takes up a radical participant perspective in that it studies what participants themselves orient to and treat as relevant in the interaction. Conversation analysts do not claim to unveil the expression (or the intention) of the individual mind, rather they aim to describe "what is out there in the material world, as it is perceived and oriented to by participants" (Sahlström, 2009, p. 105).

Within the research field of reading, some researchers have devoted their attention to how other semiotic resources than talk, such as gestures and artefacts, are used by teachers in the teaching of English (Bourne \& Jewitt, 2003) and in reading strategy instruction (Shanahan \& Roof, 2013). Analysing the practices that takes place in the classroom from a social semiotic perspective, these studies tend to focus on bodily conduct more as phenomena that have an inherent meaning (shaped through cultural, historical and social usage) rather than public social ones. That is, they do not, as this study does, attend to how temporally unfolding deployment of bodily conduct serves as a public, interactive resource on which participants may build locally relevant action. Neither do they approach human action and interaction with the microanalytic focus on the formation of action sequences that has developed within the research field of CA, the approach adopted in this article.

\section{Theoretical and Methodological Framework}

Taking as a point of orientation that action is constituted through participants' simultaneous use of different semiotic resources in face-to-face human interaction, a CA approach to multimodal interaction will be used below when analysing a literature discussion carried out by four boys in upper secondary school. CA is a research discipline that has its origin in social constructionism, and one of its points of departure is that both meaning and understanding are "established, sustained and changed in and through the coordinated interaction of people" (Sahlström, 2009, p. 103) and the interaction between people and artefacts in specific social and cultural contexts (Drew \& Heritage, 2006; Goodwin, 2000; Schegloff, 2007).

Another central principle in CA is that it takes a radical participant perspective. What is to be studied is how conversation participants carry out courses of collaborative actions together, how they show their interpretation and understanding of each other's actions and what this generates in terms of new actions (Goodwin, 2000; Hutchby \& Wooffitt, 1998; Schegloff, 1996, 2006). In the work of identifying the aspects of a conversation that participants themselves make relevant, and to show this in a convincing way to other researchers, CA research has developed a method that Sacks et al. (1974) calls "proof procedure". This involves the use of the participants' demonstrated understanding of each other's actions as a resource in the analysis and as a means of enabling readers to judge the claims of the analyst. In this work, CA uses detailed representations of the interaction, which will be presented in this article as detailed transcriptions of spoken data, as well as drawings of visual phenomena in the literature discussion.

In CA, verbal and non-verbal language are seen as tools through which participants in a conversation construct and reconstruct their social reality; thus not only talk but also other semiotic resources such as gazes, gestures, body movements and physical objects are seen as constitutive of and integral parts of the ongoing interaction. A reconceptualisation of embodied interaction (including talk) in the material world as multimodal, and a recognition of the 
importance of drawing attention to how physical objects in the environment are drawn into the production of inter-subjective understanding, are priorities in using this analytic framework (Streeck, Goodwin \& LeBaron, 2011).

One of the leading CA researchers who has developed such a perspective is Charles Goodwin (2000, 2003, 2006, 2013); other works have emerged in line with his research that examine how talk and embodied actions mutually contextualise each other on a moment-bymoment basis, and how these semiotic resources provide a resource for participants to organise, interpret and understand each other's contributions to the interaction in the ongoing activity (Goodwin \& Cekaite, 2013; Heath, Luff \& Knoblauch, 2004; LeBaron, Glenn \& Thompson, 2009; Streeck, 1993, 1994, 2003).

In this article the relationship between talk and bodily conduct will be viewed as processes that mutually contextualise one another, providing public resources for the participants to organise relevant actions that, in concert with each other, contribute to the ongoing activity (Asplund \& Kilbrink, 2016; Goodwin, 2000, 2006; Streeck, Goodwin \& LeBaron, 2011). This approach will be used with the aim of showing that actions are constructed through the simultaneous use of multiple semiotic resources, and that it is important to pay attention not only to the vocal communication between participants in a literature discussion but also to the embodied practices of both the speaker and the listener. In this respect, the article takes its point of departure in spoken language, embodied actions and artefacts as used in concert with each other to construct meaning and understanding in the interaction, which is also very much tied to the specific local context in which it occurs (Goodwin, 2000, 2007) and to the fact that it is essential to take this into consideration when analysing literature discussions. Thus, approaching multimodal interaction in a CA framework, this article aims to broaden and develop the methodological discussion of using and analysing video data in the study of literature discussions, and to contribute to a growing body of knowledge about the complex meaningmaking processes that are set into play when students interact with literary texts in school.

\section{The Research Design}

A sequence from one literature discussion will be presented and analysed in this article. Those carrying out the discussion are four boys (ages 16-17) who attend a traditionally maledominated vocational programme (the Vehicle Engineering programme) providing training for jobs such as car mechanics, truck drivers or excavators. The boys are in the same class, there are no girls in the class and the upper secondary school where the boys study is located in a rural setting in central Sweden.

During the years 2005-2008 the Author of this article lived and worked as a researcher and teacher in the classroom that was being studied, collecting extensive ethnographic data (Delamont \& Atkinson, 2008) such as observation notes, all the pupils' written work, surveys, interviews and about 30 hours of audio and video recordings of some of the teaching lessons. In this article I will concentrate on one of the video-recorded peer-led literature discussions in which Niklas, Krister, Peter and Jonas (all pseudonyms) participated as part of their Swedish language instruction, and I will focus on a specific sequence in this discussion with the aim of examining how the boys use talk, embodiments and artefacts from the surrounding context when talking about their readings of a translated version of John Marsden's novel Tomorrow When the War Began (1993). The novel is about a group of Australian teens who take action towards waging a guerrilla war against a foreign force that has occupied their country. The novel, which depicts the teens struggling for survival, was part of a larger thematic project on heroes and role 
models that the class was involved in as part of their Swedish language course when the literature discussion took place. The boys had been instructed by their teacher to discuss the plot of the novel briefly and to talk about their reading experiences and discuss the various characters' actions and motivations and relate them to the thematic work on courage, morality and heroism.

Since the article's primary aim is to focus on methodological issues surrounding how to approach video-recorded data when analysing literature discussions, I will not discuss the boys' comprehension and responses to the novel in great detail. For the same reason, I will not discuss any educational settings that may have had an impact on the discussion.

At the beginning of the boys' conversation, the teacher moved between their group and another in the classroom. In the sequence analysed in this article, the teacher was not present in the group. The film camera recording the boys' conversation was equipped with a wide-angle lens and positioned at the front of the classroom on a TV stand.

The analysis of the boys' literature discussion is presented below with a transcript that reflects certain aspects of the interaction. Square brackets ( [ ) in vertical line positions indicate simultaneous talk. A parenthetical dot indicates a short break, a "micropause" ( $<1 \mathrm{~s})$, while numbers in parentheses indicate a pause in seconds. Double "more than" $(>>)$ means that the turn continues on another line, while text in double parentheses is relevant information from the Author. Empty parentheses are used when something is being said that was inaudible, while a whole word (or part) is underlined when it was uttered in a louder voice than usual.

The article focuses on how the participants in the conversation used their bodies and how they brought physical objects into the interaction; in this context I make use of illustrations to show how the boys used their bodies and artefacts as semiotic resources in the interaction (an approach which is commonly used within the CA research tradition (see e.g., Goodwin, 2000, 2006; Melander \& Sahlström, 2009). Five illustrations in which the boys' bodily conduct is especially evident are represented in the article. For reasons of lack of space, I have chosen not to use more illustrations but to describe the boys' bodily conduct in double parentheses. To show more precisely where in the conversation the illustrated act was performed, I present the transcript, with the words being said at the time, using an external frame. Arrows in the drawings are used to indicate the directions of the gestures, lines are used for gaze. For ethical reasons, I chose not to make use of still images of the recorded material.

\section{The Boys' Literature Discussion}

\section{Findings}

Parking a tanker truck. The boys discuss the novel for about 20 minutes. In the sequence presented below, they are sorting out one of many events in the novel when a controversy emerges regarding how one of the characters in the novel, Ellie, parks a tanker truck under a bridge. Ellie and her friends will then set the tanker truck on fire so it will explode, and the bridge will be destroyed. It is of no importance to the plot how the tanker truck was parked, but the boys' dialogue shows that this is important to them and their readings of the novel.

1. Krister: But that ( . ) but I don't understand that. They had a car and a trailer with them, didn't

2.

they?

3. Niklas: ( )

4. Peter: Yes, trailer.

5. Krister: $\quad$ Like ( . ) it must be a terribly wide bridge if the car can fit under the bridge.

6. (1.0) 
7. Peter: Y[es.

8. Jonas: $\quad$ [Well, it depends on how you park it. ((Puts a pen on the desk.))

9. Niklas: They [( )

10. Jonas: [If you park it parallel with the bridge [like this. ((Moves his right arm/hand 11. back and forth along with the pen that lies on the desk.))

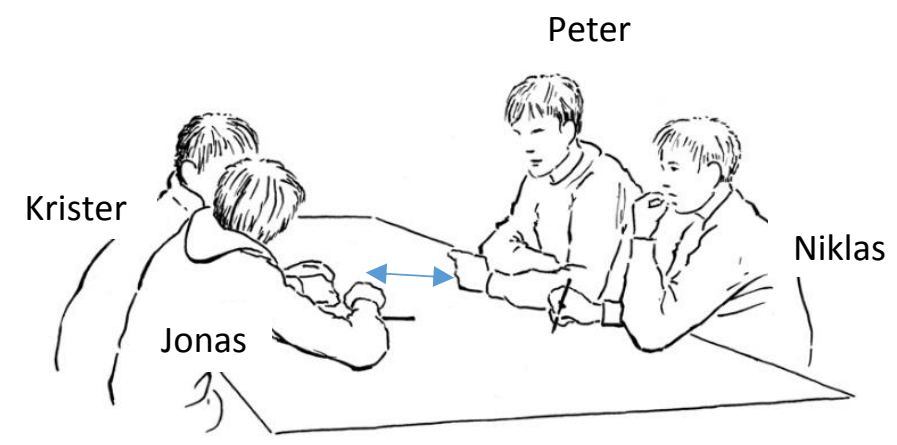

12. Krister: 13. Jonas:

[No, you couldn't have done that.

14. the pen that lies on the desk.))

15. Krister: $\quad$ Yes!

$16 . \quad(1.0)$

17. Niklas: Yes, they did [too!

18. Krister: $\quad$ [They did too, because she parked just so that they couldn't $>>$

19. Peter: $[($ )

20. Krister: > out ( . ) the passenger could open toward the pillar. ((Makes gestures with both his 21. hands towards the pen.))

22. Jonas: Yes, but then the pillar could [be like >>

23. Peter:

24. Jonas:

[She can park like this too.

25. Peter: The pillar can be like this. ((Moves his index fingers towards the desk.))

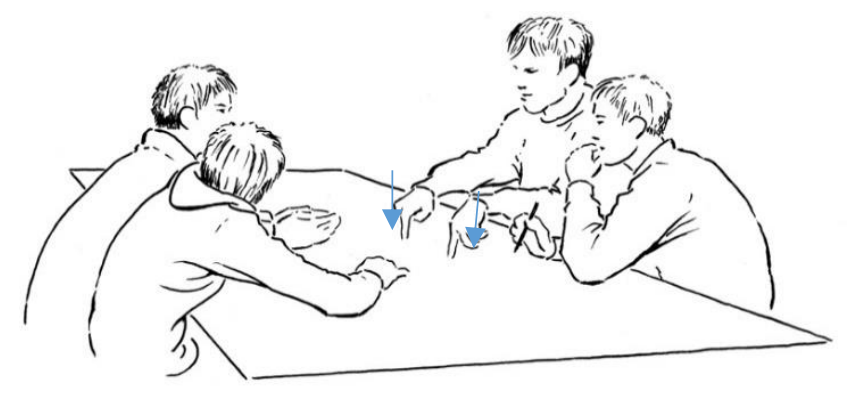

26. [And then it's parked-

27. Krister: [Well, that's true. But as I understood it, they were just driving straight under.

28. ((Moves his left hand in a straight forward direction.)) 


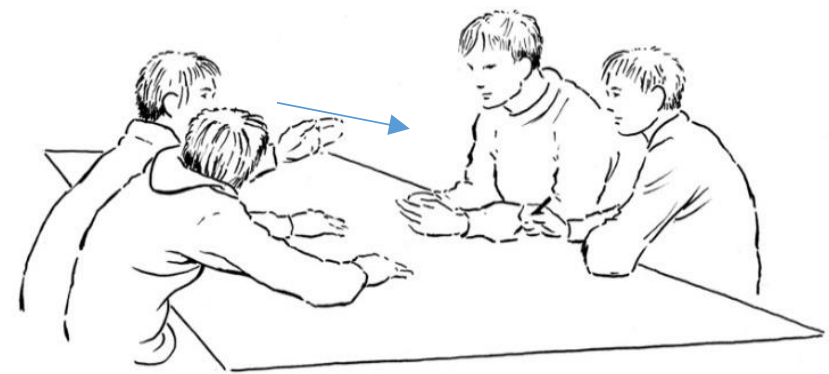

29. Jonas: $\quad$ Yes, but it can be straight under like that too. ((Nods towards Peter.))

30. Niklas: Yeah, yeah [they parked the lorry under the bridge, anyhow!

31. Jonas:

32.

[Yeah, but if you stand like this, it's quite stupid to drive like this to park

33. Niklas: Hey you! [They parked the lorry under the bridge, so it's cool, okay! ((Grabs Jonas's

34. arm and looks at him, and then he looks at Krister.))

35. Krister:

36. Peter:

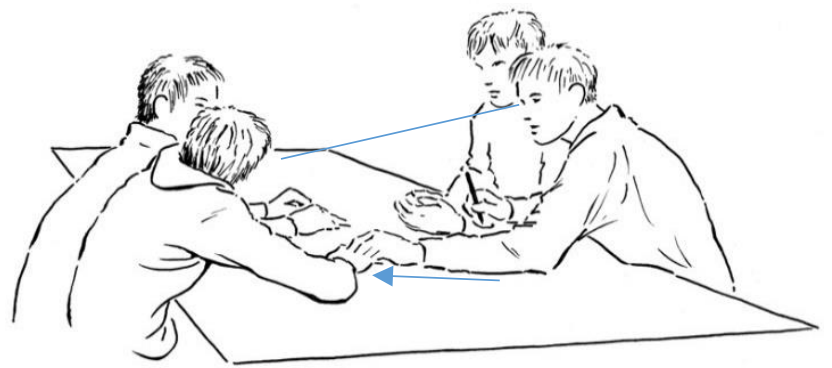

37. Krister:

38.

[Did too.

Y[es.

39. Jonas: $\quad$ Yes!?

40. Niklas: $\quad$ Oh my, oh my, oh my! ((Looks at Peter and shakes his head.))

41. Krister: $\quad$ So I don't know if they were driving over, I don't know if they were driving like this

42.

43.

44. Jonas: No ( . ) but ( . ) we can assume that they were driving under like this because [( )

45. then. ((Moves his right hand straight forward along with the pen.))

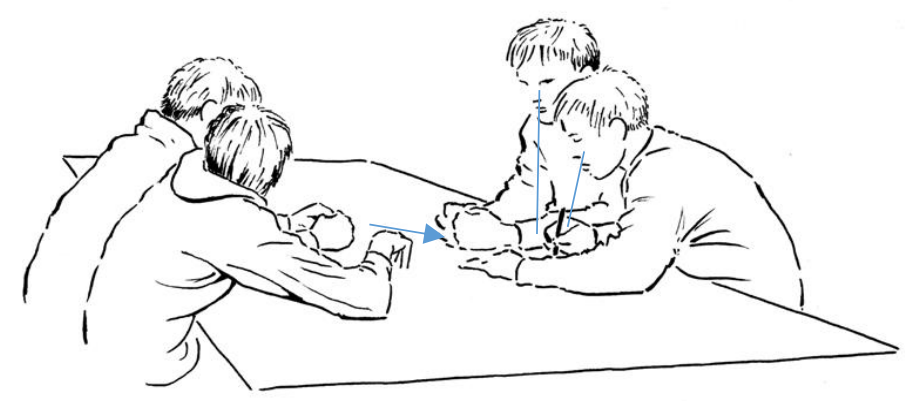

46. Niklas:

47.

then they ran like crazy then.

[And 
Krister emerges as the most ardent proponent of the conception that the tanker truck was parked perpendicular to the bridge (i.e. intersecting the driving direction), while primarily Jonas claims that the truck was parked parallel with the bridge (in the driving direction). In the excerpt, the boys then relate to these two attitudes.

Using different kinds of signs. The sequence begins when Krister, on lines 1 and 5, says that he doesn't really understand how the tanker truck was parked. In Krister's view an extremely wide bridge is required to allow a tanker with its trailer to fit under the bridge, and Krister says he doesn't really understand how this could be done. Krister's opinion prompts Jonas (lines 8, 10-11) to claim that parking the tanker truck is quite possible to envisage, if one imagines that it was parked parallel with the bridge: "Well, it depends on how you park it. If you park it parallel with the bridge like this." While making his statement Jonas takes his pen and puts it on the table, and when he says "like this" (see line 10) he moves his right hand straight forward. As soon as Jonas puts the pen on the table, it becomes implicated in the interaction and when he says the word "bridge" and moves his right hand forward along with the pen, the pen turns into a bridge and it is in relation to this pen/bridge that Jonas highlights how the tanker truck was parked.

What is thus happening in lines 8-11 is that Jonas, in reaction to Krister's questions and comments about how the tanker truck was parked, builds up a scene from the novel, fully visible on the desk in front of the other boys. His action is constructed here through the simultaneous use of different semiotic resources; his talk is filled with the combination of a pen and his body movements, and as we follow the boys' interaction in the excerpt we can see that the other boys show that they understand what Jonas is telling them.

This can be seen for instance by the fact that the pen, from this point on, is the basis and starting point for the boys' continued discussion about the parking scene in the novel, i.e., the boys continue to relate to the pen as a bridge; it becomes implicated in collaborative, symbolic action (see Streeck, 2011). The discussion that continues deals with how the tanker truck was parked, i.e. if it was parked parallel with the bridge or if it was parked in a direction intersecting the driving direction.

What is interesting in this context is that the other participants' actions are also constructed through the simultaneous use of multiple semiotic resources, and in order to understand, as an analyst (and participant), what they are communicating we must take into account all the different kinds of signs that are being used in the interaction. If we only took into account what the boys say, i.e. their talk, we would find it difficult to understand parts of their conversation, as some of the phrases they use are inconclusive.

When, as an example, Peter says "The pillar could be like this", after Krister has said that the tanker truck was parked next to a pillar in such a way that the passenger door could not be opened (lines 18, 20-21), it is difficult to understand what Peter means if we only focus on what he says. That the pillar can be "like this" can of course mean many different things, since Peter never specifies "like this" with his talk. But if we pay attention to what he is doing with his body while he makes his utterance, we find that he completes it by moving his index fingers towards the desk.

Then, in the same way as the pen was made into a bridge by Jonas's action earlier in the excerpt, Peter's index fingers are transformed into two pillars for a brief moment, until he folds his arms and puts his hands together again. Thus, taking Peter's embodied actions into consideration, his talk suddenly makes sense, and as we can see, the other participants don't treat 
his talk as faulty, rather they show that they understand him by relating to his action in various ways (see also Streeck, Goodwin \& LeBaron, 2011).

A similar action is the one done by Jonas in line 29. In the line above (line 28), Krister repeats his perception of how the tanker truck was parked (supplementing it this time by pointing straight ahead). Jonas objects by saying, "Yes, but it may well be straight under like that too." Again, if we only take into account what Jonas says it would be hard as an analyst to form an idea of what Jonas is trying to say, since he doesn't clarify what he means by "like that." However, taking into account what Jonas does with his body during the talk we can see that he nods towards Peter when he says "like that." Parking the tanker truck "straight under like that" thus means to park it the way Peter has argued earlier in the conversation (when he uses his index fingers). Jonas thereby takes the same stance as Peter.

Co-occurring actions. The significance of paying attention to how participants use semiotic resources when interacting with each other is particularly clear when we take a closer look at what is happening in lines 30-46. There were namely several things co-occurring in the previous illustration that give us information about what was happening in the interaction information that would have gone unnoticed if we had focused on the spoken language only.

In lines 44-45, Jonas repeats the stance he presented at the introduction of the excerpt (i.e. that the tanker truck was parked parallel with the bridge, in the driving direction), using his talk, gestures and the pen in the interaction. When he does that, Niklas is not paying attention to what he is communicating. Instead, Niklas is occupied with writing something on a piece of paper in front of him. His gaze is pointed down, towards the paper on the desk, with his pen against it, indicating that he is writing or drawing something on it. This is an act that the other participants can observe, and as we can see, Peter is the one who is following Niklas moving his pen with his gaze while Jonas directs his focus on Krister.

The fact that Niklas is paying attention to something other than Jonas's act can be interpreted as his having lost interest in the discussion of how the tanker truck was parked. This interpretation is reinforced if we also pay attention to what Niklas is doing just before and just after this action. In lines 30 and 34-35, Niklas expresses the idea that the boys should just agree that the tanker truck was parked under the bridge and that it is less important to sort out (and agree on) how it was parked. In lines 34-35, he also turns to Jonas and says "Hey you! They parked the lorry under the bridge, so it's cool, okay?" while looking at him and grabbing his arm.

By analysing how Niklas uses talk and embodied actions it is possible for us to observe that he is addressing Jonas with his talk. Niklas gets no support, however, for his appeal; instead Krister and Jonas continue their exchange of views on how the tanker truck was parked, whereby Niklas exclaims "Oh my, oh my, oh my!" as he shakes his head and looks at Peter, probably to seek support for his disappointment in a continuation of the discussion. Then right after Jonas has repeated his stance (lines 44-45) and Niklas has turned his attention to his paper and pen, Niklas changes the topic in the conversation by saying, "And then they ran like crazy!"

By taking a closer look at how Niklas uses talk and embodied actions in concert with the other participants' actions during a longer sequence in the conversation, it is possible to systematically examine the practices he uses in the literature discussion and to understand what he is doing. If we had only paid attention to Jonas's talk in lines 44-45, and not examined other kinds of semiotic resources and meaning-making practices that the boys themselves treat as relevant in the interaction, the analysis, and our understanding of the boys' interaction, would have been incomplete. 


\section{Conclusion}

Through the analytic framework used to examine the boys' literature discussion, this article moves beyond the previous studies of literature discussions that focus on verbal language as the baseline for their understanding of the meaning-making practices that take place within literature discussions. If such a perspective had been the baseline of this analysis, it would have been much harder, if at all possible, to make any sense of how the boys construct meaning from their readings when they discussed the novel.

The actions that take place when the boys discuss their readings of the novel are, as have been examined in this article, simultaneous and collaborative through the boys' constructed actions, and the meaning-making practices are constructed through the mutual elaboration of several different kinds of semiotic resources, such as talk, gestures, gazes and physical objects. When discussing the parking scene in the novel, the boys are eager to explain to each other how they construct meaning from it, and the analysis shows that their perceptions differ depending on the projected images lived in their literary experiences. Using Rosenblatt's terminology (1978/1994) here, it is the efferent mode of reading that comes to the fore in the focus on the parking scene in the boys' conversation. In contrast to the aesthetic mode in which the reader's attention is centered on what he is living through during the encounter with the text, the reader's primary concern in responding in the efferent mode is with what he will carry away from the reading. In the efferent mode of reading, the reader has a clearly focused attention on what the words point to, in order to acquire and retrieve particular information that will serve the reader's practical purposes. When discussing the parking scene, it is clear that the boys' embodied actions help them demonstrate their readings and perceptions of the novel, here and now. As Sumara (2003) points out, "reading is the act of continually noticing and interpreting links between and among different 'bodies' that comprise our physical, psychic and ecological experience of the world" (p. 92), and when the boys are exchanging experiences of the text they have read, their verbal language is supported by other semiotic resources. Through this interchange, the boys encourage each other to express their unique responses to the text.

Thus, using a CA framework on multimodality, the article shows that it is important that we as analysts, and teachers, pay attention to what the participants themselves are orienting to and treating as important in order to gain an understanding of how participants construct meaning and understanding when interacting with literary texts in a school context.

The production of the boys' embodied actions are thus not merely private psychological phenomena, nor pre-determined, but, as shown in this article, publicly visible and, therefore, to be seen and taken into account as meaning-making actions. These meaning-making actions, constructed by a speaker, are interpreted and acted upon by the speaker's co-participants (Goodwin, 1996, 2000; LeBaron \& Streeck, 2000). If we as analysts and teachers wish to increase our understanding of what is going on when our students perform literature discussions in our classrooms, we need to pay attention to how participants' talk, bodily conduct and use of artefacts contextualise each other, and how they provide a resource for the other participants to organise and construct relevant actions when participating in a literature discussion.

Both the social semiotic approach to multimodality, with its emphasis on the sign-maker and his or her intentions, and the view of sign-making as a social process (Jewitt, 2009), along with the CA approach adopted in this article, are valid and can contribute to advancing the study of literature discussions. But when there is a specific interest and analytical focus on interaction, and when researchers want to examine how multiple semiotic resources are handled, 
collaboratively recognised and integrated into the organisation of a literature discussion, it is my belief that the CA perspective, with its microanalytic focus on interaction, is especially appropriate.

The findings in this article suggest that a CA approach to multimodal interaction that takes a radical participant perspective (Schegloff, 1996) and assumes that different semiotic resources interact with each other to build locally relevant action (Goodwin, 2000, 2013; Schegloff, 2006) can contribute to increasing our understanding of the complex meaning-making processes that are set into play when students interact on literary texts in school. The approach thus makes it possible to show how theories of multimodality are set into practice when students discuss and negotiate their interpretations of what they have read, and this study may, therefore, develop teachers' analytical “metalanguage” (New London Group, 1996, p. 77) - i.e. their professional language for talking about reading instruction and meaning-making interactions in classroom practice.

\section{References}

Almasi, J.F., O'Flavahan, J.F. \& Aryha, P. (2001). A comparative analysis of student and teacher development in more and less proficient discussions of literature. Reading Research Quarterly, 36(2), 96-120.

Alvermann, D., Young, J.P., Weaver, D., Hinchmann, K., Moore, D., Phelps, S., Trasch, E. \& Zalewskij, P. (1996). Middle and high school students' perceptions of how they experience text-based discussions: A multicase study. Reading Research Quarterly, 31(3), 244-267.

Anmarkrud, Ö. \& Bråten, I. (2012). Naturally-occurring comprehension strategies instruction in $9^{\text {th }}$-grade language arts classrooms. Scandinavian Journal of Educational Research, 56(6), 591-693.

Asplund, S-B. (2010). Läsning som identitetsskapande handling. Gemenskapande och utbrytningsförsök i fordonspojkars litteratursamtal. [Reading as identity construction. Practices and processes of building a sense of community in literary discussions among male Vehicle Engineering students]. Karlstad University Studies, nr. 2010:4, Karlstad: Karlstad University. (diss.)

Asplund, S-B. (2012). Being a skilled reader: Reception patterns in vehicle engineering students' literature discussion. Education Inquiry 3(2), 243-257.

Asplund, S. B., \& Kilbrink, N. (2016). Learning How (and How Not) to Weld: Vocational Learning in Technical Vocational Education. Scandinavian Journal of Educational Research, 1-16.

Asplund, S-B and Pérez Prieto, H. (2013). 'Ellie is the coolest': Class, masculinity and place in vehicle engineering students' talk about literature in a Swedish rural town school. Children's Geographies 11(1), 59-73.

Bourne, J. \& Jewitt, C. (2003). Orchestrating debate: a multimodal analysis of classroom interaction. Reading, (37)2, 64-72.

Chinn, C.A., Anderson, R.C. \& Waggoner, M.A. (2001). Patterns of discourse in two kinds of literature discussion. Reading Research Quarterly, 36(4), 378-411.

Delamont, S. \& Atkinson, P.A. (2008). Representing Ethnography: Reading, Writing and Rhetoric in Qualitative research. London: Sage Publications. 
Drew, P. \& Heritage, J. (2006). “Editors' Introduction”. In P. Drew and J. Heritage (Eds.), Conversation Analysis (Volume 1) (pp. xxi-xxxvii). London: Sage.

Dutro, E. (2001). "But that's a girl's book!" Exploring gender boundaries in children's reading practise. The Reading Teacher, 55(4), 376-384.

Enfield, N.J. \& Levinson, S.C. (2006). Introduction: Human sociality as a new interdisciplinary field. In N. J. Enfield, \& S. C. Levinson (Eds.), Roots of Human Sociality: Culture, Cognition and Interaction (pp. 1-35). Oxford: Berg.

Evans, K.S. (1996a). A closer look at literature discussion groups: The influence of gender on student response and discourse. The New Advocate, 9(3), 183-196.

Evans, K.S. (1996b). Creating spaces for equity? The role of positioning in peer-led discussions. Language Arts, 73(3), 194-202.

Evans, K.S. (2002). Fifth-grade students' perceptions of how they experience literature discussion groups. Reading Research Quarterly, 37(1), 46-69.

Evans, K.S., Alvermann, D.E., \& Anders, P.L. (1997). Literature discussion groups: An examination of gender roles. Reading Research and Instruction, 37(2), 107-22

Gilje, O. (2009). Mode, Mediation and Moving Images: An Inquiry of Digital Editing Practices in Media Education, Faculty of Education, University of Oslo, Norway. (Diss.)

Goodwin, C. (1996). Transparent vision. In E. Ochs, E. Schegloff \& S. Thompson (Eds.), Interaction and Grammar (pp. 370-404). Cambridge: Cambridge University Press.

Goodwin, C. (2000). Action and embodiment within situated human interaction. Journal of Pragmatics, 32(10), 1489-1522.

Goodwin, C. (2003). The semiotic body in its environment. In J. Coupland \& R. Gwyn, Discourses of the Body (pp. 19-42). New York: Palgrave/Macmillan.

Goodwin, C. (2006). Human sociality as mutual orientation in a rich interactive environment: Multimodal utterances and pointing in aphasia. In N.J. Enfield \& S.C. Levinson (Eds.), Roots of Human Sociality: Culture, Cognition and Interaction (pp. 97-125). Oxford/New York: Berg Publishers.

Goodwin, C. (2007). Environmentally coupled gestures. In S. Duncan, J. Cassell \& E. Levy (Eds.), Gesture and the Dynamic Dimension of Language (pp. 195-212). Amsterdam/Philadelphia: John Benjamins.

Goodwin, C. (2010). Construction meaning through prosody in aphasia. In D. Barth-Weingarten, E. Reber \& M. Selting, (Eds.), Prosody in Interaction (pp. 373-394). Amsterdam: Philadelphia: Benjamins.

Goodwin, C. (2013). The co-operative, transformative organization of human action and knowledge. Journal of Pragmatics, 46(1), 8-23.

Goodwin, M. H. \& Cekaite, A. 2013. Calibration in directive/response sequences in family interaction. Journal of Pragmatics, 46(1), 122-138.

Goodwin, M.H. \& Goodwin, C. (2012). Car talk: Integrating texts, bodies, and changing landscapes. Semiotica, 191, 257-286.

Granly, A. \& Maagerø, A. (2012). Multimodal texts in kindergarten rooms. Education Inquiry 3(3), 371-386.

Heath, C.C., Luff, P. \& Knoblauch, H. (2004). Tools, technologies and organizational interaction: The emergence of 'workplace studies'. In D. Grant, C. Hardy, C. Oswick \& L. Putman (eds.), The Handbook of Organizational Discourse (pp. 337-359). London: Sage. 
Hutchby, I. \& Wooffitt, R. (1998). Conversation Analysis: Principles, Practices and Applications. Cambridge: Polity Press.

Jewitt, C. (2003). Re-thinking assessment: multimodality, literacy and computer mediated learning. Assessment in Education, 10(1), 82-102.

Jewitt, C. (2005). Classrooms and the Design of Pedagogic Discourse: A Multimodal Approach. Culture and Psychology, 11(3), 309-320.

Jewitt, C. (2008). Teachers' pedagogic design of digital interactive whiteboard materials in the UK secondary school. Designs for Learning, 1(1), 42-54.

Jewitt, C. \& Kress, G. (Eds.) (2003). Multimodal Literacy. New York: Peter Lang.

Kress, G. (2010). Multimodality. A Social Semiotic Approach to Contemporary Communication. London: Routledge.

Kress, G. \& van Leuwen, T. (2001). Multimodal Discourse. The Modes and Media Contemporary Communication. London: Arnold.

Kress, G., Jewitt, C., Ogborn, J. \& Tsatsarelis, C. (2001). Multimodal Teaching and Learning: The Rhetorics of the Science Classroom. London: Continuum.

Kress, G., Jewitt, C., Bourne, J., Franks, A., Hardcastle, J., Jones, K. \& Reid, E. (2005). Urban Classrooms, Subject English: Multimodal Perspectives on Teaching and Learning. London: Routledge Falmer.

Kääntä, L. (2014). From noticing to initiating correction: Students' epistemic displays in instructional interaction. Journal of Pragmatics, 66, 86-105.

Langer, J. A. (2011). Envisioning Literature: Literary Understanding and Literature Instruction. Teachers College, Colombia University: New York and London.

Lebaron, C., Glenn, P. \& Thomson, M. (2009). Identity work during boundary moments: Managing positive identities through talk and embodied interaction. In J. Dutton \& L. Roberts (Eds.), Exploring Positive Identities and Organizations: Building a Theoretical and Research Foundation (pp. 187-211). New York: Routledge.

Lebaron, C. \& Streeck, J. (2000). Gestures, knowledge, and the world. In D. McNeill (Ed.), Language and Gesture: Windows into Thought and Action (pp. 118-138). Cambridge: Cambridge University Press.

Lee, H-C. (2013). An examination of ESL Taiwanese University students' multimodal reading responses. Literacy Research and Instruction, 52(3), 192-203.

Maloch, B. (2002). Scaffolding student talk: One teacher's role in literature discussion groups. Reading Research Quarterly, 37(1), 94-112.

Marsden, J. (1993). Tomorrow, When the War Began. Chippendale: Pan Macmillan.

Marshall, J.D. (1989). Patterns of Discourse in Classroom Discussions of Literature. Albany, New York: CELA Report Series 2.9.

McCormick, K. (1994). The Culture of Reading and the Teaching of English. Manchester: Manchester University Press.

Melander, H. \& Sahlström, F. (2009). In tow of the blue whale: Learning as interactional changes in topical orientation. Journal of Pragmatics, 41, 1519-1537.

Murphy, P.K., Wilkinson, I.A.G., Soter, A.O., Hennessey, M.N. \& Alexander, J.F. (2009). Examining the effects of classroom discussion on students' comprehension of text: A meta-analysis. Journal of Educational Psychology, 101(3), 740 -764.

The New London Group. (1996). A pedagogy of multiliteracies: Designing social futures. Harvard educational review, 66(1), 60-93. 
Nystrand, M. (1997). Opening Dialogue. Understanding the Dynamics of Language and Learning in the English Classroom. New York: Teachers College Press.

Nystrand, M. (2006). Research on the role of classroom discourse as it affects reading comprehension. Research in the Teaching of English, 40, 392-412.

Raphael, T. E., Gavelek, J. R. \& Daniels, V. (1998). Developing students' talk about text: An initial analysis in a fifth-grade classroom. National Reading Conference Yearbook, 47, pp. 116-128.

Reninger, K.B. (2007). Intermediate-level, lower-achieving readers' participation in and highlevel thinking during group discussions about literary texts. The Ohio State University. [Electronic version]. Downloaded from http://etd.ohiolink.edu/.2013-06-04.

Rogers, R. \& Mosley, M. (2006). Racial literacy in a second-grade classroom: Critical race theory, whiteness studies, and literacy research. Reading Research Quarterly, 41(4), 462495.

Rosenblatt, L.M. (1994). The reader, the text, the poem. The transactional theory of literacy work. Carbondale, IL: Southern Illinois University Press. (Original work published 1978)

Rosenblatt, L.M. (1995). Literature as exploration. New York: MLA. (Original work published 1938)

Sacks, H., Schegloff, E., \& Jefferson, G. (1974). A simplest systematics for the organization of turn-taking for conversation. Language, 50, 696-753.

Sahlström, F. (2009). Editorial. Scandinavian Journal of Educational Research, 53(2), 103-111.

Shanahan, L. E. \& Roof, L.M. (2013). Developing strategic readers: A multimodal analysis of a primary school teacher's use of speech, gesture, and artefacts. Literacy, 47(3), 157-164.

Schegloff, E.A. (1996). Confirming allusion: Toward an empirical account of action. The American Journal of Sociology, 102, 161-216.

Schegloff, E.A. (2006). Interaction. The infrastructure for social institutions, the natural ecological niche for language, and the arena in which culture is enacted. In N.J. Enfield and Stephen C. Levinson (Eds.), Roots of Human Sociality. Culture Cognition and Interaction (pp. 70-98). Oxford: Berg.

Schegloff, E.A. (2007). Sequence Organization in Interaction. A Primer in Conversation Analysis 1. Cambridge: Cambridge University Press.

Soter, A.O., Wilkinson, I.A.G, Murphy, P.K., Rudge, L., Reninger, K. \& Edwards, M. (2008). What the discourse tells us: Talk and indicators of high-level comprehension. International Journal of Educational Research, 47, 372-391.

Streeck, J. (1993). Gesture as communication I: It's coordination with gaze and speech. Communication Monographs, 60, 275-299.

Streeck, J. (1994). Gesture as communication II: The audience as co-author. Research on Language and Social Interaction, 27(3), 239-267.

Streeck, J. (2003). The body taken for granted: Lingering dualism in research on social interaction. Studies in Language and Social Interaction: In P. Glenn, C.D. LeBaron \& J. Mandelbaum, In Honor of Robert Hopper. (Eds.) (pp. 427-440). Mahwah, NJ: Lawrence Erlbaum.

Streeck, J. (2011). The changing meanings of things: Found objects and inscriptions in social interaction. In J. Streeck, C. Goodwin \& C. LeBaron (Eds.). Embodied Interaction. Language and Body in the Material World (pp. 67-78). Cambridge: Cambridge University Press. 
Streeck, J., Goodwin, C. \& LeBaron, C. (Eds.). (2011). Embodied Interaction: Language and Body in the Material World. Cambridge: Cambridge University Press.

Sumara, D. (2003). Towards a theory of embodied literary experience. English Teaching: Practice and Critique, 2(2), 88-95.

Säljö, R. (2011). Kontext och mänskliga samspel. Ett sociokulturellt perspektiv på lärande. [Context and interaction: A sociocultural perspective on learning]. Utbildning \& Demokrati 2011, 20(3), 67-82.

Tabensky, A. (2008). Expository discourse in a second language classroom: How learners use Gesture. In S.G. McCafferty \& G. Stam (Eds.), Gesture: Second Language Acquisition and Classroom Research (pp. 298-320). London: Routledge.

Taylor, R. (2012). Messing about with metaphor: Multimodal aspects to children's creative meaning making. Literacy, 46(3), 156-166.

Tengberg, M. (2011). Samtalets möjligheter. Om litteratursamtal och litteraturreception $i$ skolan. [Potentials of discussion. On literature discussions and literary reception in school]. Brutus Stockholm/Stehag: Östlings Bokförlag Symposion. (Diss.)

Author Biography

Stig-Börje Asplund is a senior lecturer at the Department of Educational Studies at Karlstad University in Sweden. He holds a PhD in Educational Work, and his main research interest is on classroom interaction and life story approaches, with a special focus on processes of identity construction and on boys' and young men's reading in and outside school. 